Journal of

Back and

Musculoskeletal

Rehabilitation

\title{
Calendar
}

\section{Symposium on Osteoporosis: Fractures, Back Pain, Disability - Management}

\author{
June 3-5, 1999, Hotel Hilton Vienna, Austria
}

\section{Main Topics:}

Epidemiology and pathophysiology of osteoporosis

Biomechanics of bone

Osteoporosis - diagnostic tests

Sports and exercise in osteoporosis

Predictors of osteoporotic fractures

Prevention of falling

Treatment and prevention of osteoporosis

Disability and pain treatment

Complaints related to osteoporosis

Diet - nutrition and bone (how not to increase body weight)

Fracture management in osteoporosis

Osteoporosis - quality of life

\section{Information and Registration:}

Scientific and Administrative Secretariat

Vienna Academy of Postgraduate Medical Education and Research

Alser Strasse 4, A-1090 Vienna, Austria

Phone: (+43/1) 40513 83-14, Fax: (+43/1) 405138323

E-mail:medacad@via.at

Internet: http://www.via.at/medacad

\section{Technical Exhibition:}

Medizinische Ausstellungs- $u$. Werbegesellschaft

Freyung 6, A-1010 Vienna, Austria

Phone: (+43/1) 536 63-0, Fax: (+43/1) 5356016

E-mail: maw@media.co.at 